\title{
DISCURSO EGOCÉNTRICO FRENTE A DISCURSO COOPERATIVO: HOMBRES, MUJERES Y VERBOS
}

\begin{abstract}
López González Antonio María, Discurso egocéntrico frente a discurso cooperativo: Hombres, mujeres y verbos [Egocentric Discourse vs. Cooperative Discourse: Men, Women and Verbs]. Studia Romanica Posnaniensia, Adam Mickiewicz University Press, Poznan, vol. XXXI: 2004, pp. 343-352. ISBN 83-232-1353-4, ISSN 0137-2475.

D. Tannen (1990) defines women's cooperative discourse versus men's egocentric discourse. Relating to the use of verbs, both kinds of discourse are characterized by a different use of the persons of conjugation, a lexically and semantically different selection of verbs and also diverse syntactic use of verbs. In this article, 1 show how both kinds of discourses appear in the broadcasting media, focusing on the use of verbs.
\end{abstract}

\section{INTRODUCCIÓN}

Tú no me entiendes. Con este título tan sugerente presentaba Deborah Tannen en 1990 su elaboración de la teoría de los generolectos. Hombres y mujeres hacen un uso diferenciado del lenguaje que se manifiesta a través de diferentes estrategias discursivas. Básicamente, éstas se refieren a la cortesía. La mujer, según Tannen, es una hablante más cooperativa que el hombre. El principal objetivo de una mujer en una conversación es mantener un buen entendimiento; el de un hombre informar y contar. Diferentes aproximaciones conversacionales para grupos sociales diferentes: hombres y mujeres.

La distinción sexual es socialmente significativa, es decir, no arroja información sobre una distinción biológica, sino sobre la distinción social de hombres y mujeres como grupos diferentes (Cedergren, 1983: 160). Como tales grupos, hombres y mujeres hacen un uso diferenciado de los elementos lingüísticos (léxj$\cos$, morfológicos, sintácticos, pragmáticos), lo que ha sido puesto de manifiesto por la bibliografía producida en las últimas décadas ${ }^{1}$.

'Consúltese la bibliografía anotada a propósito en Romaine (1994: 159-162) y García Moutón (1999: 91-94). 
Lakoff (1977), en un artículo ya clásico, hace un inventario de las diferencias más importantes entre hombres y mujeres al emplear el lenguaje. Estas diferencias afectan a los temas de conversación, al lenguaje gestual, a las estrategias discursivas, etc. Lakoff categoriza los elementos que tipifican el estilo comunicativo de las mujeres norteamericanas bajo tres apartados:

1. Uso de un vocabulario especializado, muy rico en los campos de la moda, cocina y decoración, uso de intensificadores imprecisos, frecuentes expresiones emotivas de amor y de pesar, pero supresión de las de hostilidad, uso de formas corteses y eufemísticas,

2. En lo fonológico, una pronunciación más correcta y tradicional, y

3. Entre las características sintáctico-pragmáticas, la utilización de preguntas con funciones declarativas, rodeos o acatamientos mediante el uso de verbos modales y manejo de unidades léxicas que indican inseguridad.

Tannen en las páginas de Tú no me entiendes define un discurso cooperativo femenino frente a un discurso egocéntrico masculino. En lo referente al uso verbal, ambos tipos de discurso se hallan marcados por la mayor frecuencia de las segundas personas (tú, vosotros, Usted) y de la primera del plural (nosotros) en el discurso cooperativo femenino, frente a la mayor abundancia de la primera persona del singular (yo) en el discurso egocéntrico masculino. Mediante estas formas, las mujeres procuran mantener el contacto con los otros participantes en la comunicación e integrarlos en el discurso, y al mismo tiempo componer lazos de solidaridad grupal. Los hombres parecen más preocupados por su estatus, de ahí la mayor frecuencia del egocéntrico "yo", según Tannen.

\section{METODOLOGÍA}

En el presente artículo me dispongo a mostrar cómo ambos tipos de discurso se manifiestan en el contexto radiofónico en relación con el uso de los verbos. Para ello he seleccionado cinco emisoras de radio de Almería, en Andalucía. Estas emisoras son:

- Alhamilla Radio (Convencional - Musical, Provincial - Almería)

- Cadena 100 (Musical - Nacional)

- Cadena COPE (Convencional, Nacional)

- Canal Sur (Convencional, Regional - Andalucía)

- Cadena SER (Convencional - Nacional)

El tipo de programas analizado pertenece al Estrato de Programación (EP) de las Misceláneas. En este tipo de programas es donde con más frecuencia se da la interacción comunicativa entre hombres y mujeres en la entrevista, la participación 
telefónica, el debate o la tertulia. Todos los textos aquí estudiados pertenecen al corpus lingüístico radiofónico de mi Tesis Doctoral. Las grabaciones se realizaron en el mes de junio de 1995. Los fragmentos analizados incluyen comentarios sobre la compra, música, poesía, noticias de actualidad, participación telefónica para felicitar o concursar, entrevistas a médicos, estudiantes de Derecho, empresarios y pescadores y un coloquio religioso.

El criterio que se siguió para la transcripción de las grabaciones fue ortográfico, realizando, en consecuencia, una transliteración (López Morales, 1994: 97) de los textos. Tras la selección de los textos a analizar, se procedió a la separación de las intervenciones masculinas de las femeninas en sendas Unidades de Texto, que son las que se comparan después.

Con el fin de que la longitud de los textos no afectase a la medición de las frecuencias verbales que pretendemos estudiar, se ha procurado que la extensión de las Unidades de Texto masculinas y femeninas fuese parecida. Así, los textos analizados varían entre un máximo de 877 palabras gráficas para los textos femeninos en Canal Sur y un mínimo de 502 palabras gráficas para los textos femeninos de la Cadena COPE. La medía tanto masculina como femenina se halla en las 748 palabras para los hombres y 707 para las mujeres. Cuando hablo de palabra gráfica, lo hago siguiendo a Ávila (1992: http://www), quien la definió en el Proyecto DIES-RTP como "una secuencia de letras antes y después de la cual aparece un espacio en blanco".

Las variables elegidas para su estudio son:
a. La densidad verbal.
b. La riqueza verbal.
c. Los verbos de acción.
d. El número de verbos en enunciados.
e. El discurso egocéntrico.
f. El discurso cooperativo.
g. La diferencia discurso egocéntrico - discurso cooperativo.

\section{ANÁLISIS}

\section{a. La densidad verbal}

Bajo este epígrafe analizamos la cantidad de verbos empleada por hombres y mujeres, por una parte contabilizando las formas personales y las no personales, y por otra sólo las formas conjugadas. 


\section{\% Verbos en tipos léxicos}

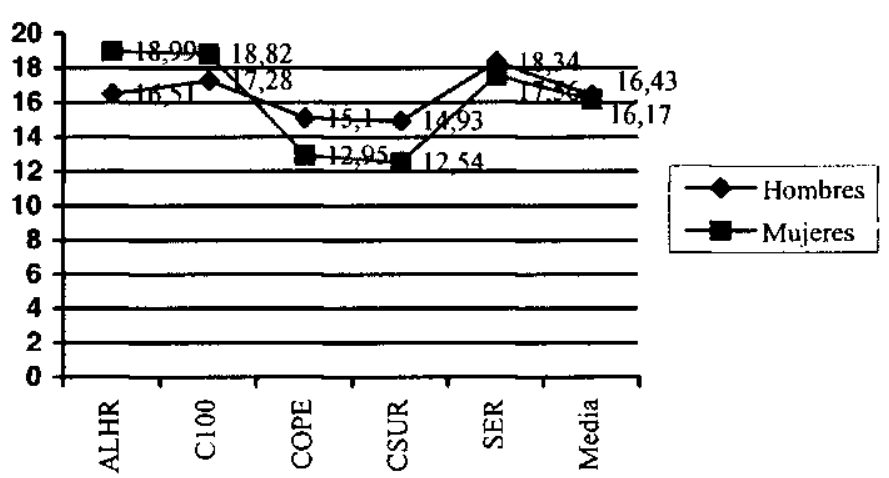

A la vista de los resultados, tanto en un caso como en el otro, no parece haber una diferencia sustancial entre hombres y mujeres, si bien la media siempre es ligeramente favorable a los hombres, en $0,26 \%$ en el caso de considerar formas personales y no personales, y en $0,44 \%$ tomando en cuenta sólo las formas conjugadas.

\section{\% Verbos conjugados en tipos léxicos}

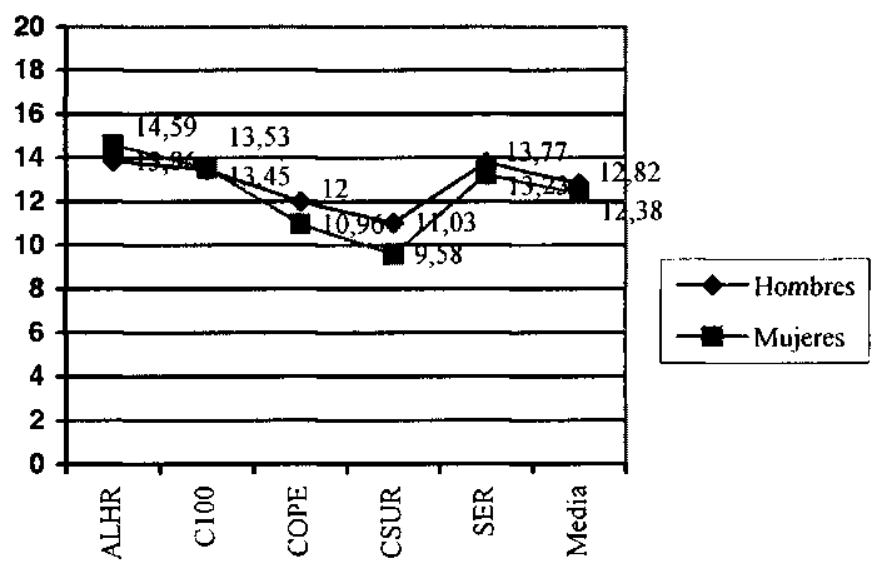

Este índice habrá de ser contrastado más tarde con los de riqueza verbal, tipos de verbos y número de verbos por enunciado para ser interpretado correctamente.

\section{b. La riqueza verbal}

El índice de riqueza verbal, cuyo valor se sitúa siempre entre 0 y 1 , nos informa de la amplitud del repertorio de formas verbales utilizadas por los 
hablantes. Es el resultado del cociente vocablos verbales / tipos léxicos verbales (incluyendo las formas no personales).

Claramente las mujeres superan a los hombres en variedad de vocabulario verbal, en 0,10 puntos sobre 1 . Especialmente ostensible se hace la diferencia a favor de las mujeres en la Cadena COPE $(0,33)$ y Canal Sur $(0,15)$. En Alhamilla Radio y la Cadena SER los índices son muy similares para ambos sexos.

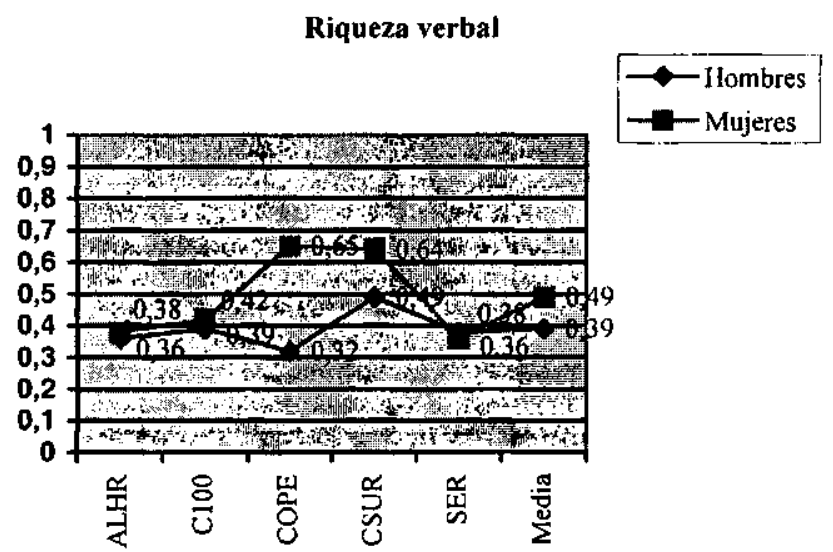

c. Los verbos de acción

Según la muestra estudiada, la categoría de verbos de acción sirve como índice definitorio de los generolectos en el uso de los verbos. Con porcentajes similares de uso en la Cadena 100 y Canal Sur, en el resto de emisoras presenta claras diferencias. Son siempre los hombres en estas emisoras los que utilizan con más frecuencia los verbos de acción. Esta diferencia llega a ser en la Cadena SER de un $25,84 \%$ a favor del sexo masculino.

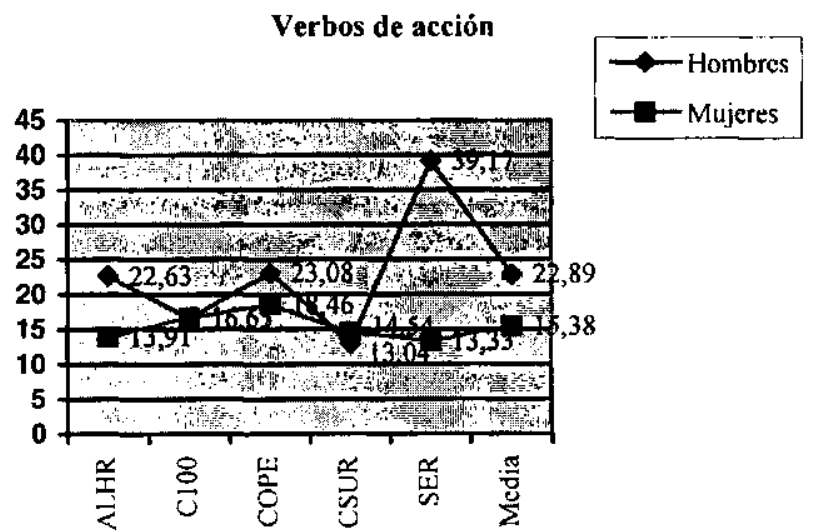


d. El número de verbos en enunciados

En palabras de Ávila (1997b: http://www.) un enunciado "es un segmento de texto autosuficiente semánticamente" que "está delimitado por puntos, signos de interrogación o exclamación". Este enunciado, además, "siempre empieza con letra mayúscula". El enunciado puede o no coincidir con la oración gramatical.

Esta "longitud se correlaciona con la mayor o menor complejidad de la oración" (Ávila, 1997b: http://www.), la cual tiene consecuencias para la inteligibilidad y comprensión del texto. Una vez aplicado el proceso de cómputo a nuestra muestra, los resultados indican que las mujeres producen enunciados más largos que los hombres, lo que viene a sugerir una mayor complejidad oracional en el grupo femenino. La excepción se plantea en la emisora andaluza Canal Sur, en la que, de cualquier modo, la diferencia a favor del grupo masculino es pequeña $(0,81 \%)$, si tenemos en cuenta que la diferencia media a favor de la mujer es de $2,36 \%$.

\section{Longitud promedio de enunciados}

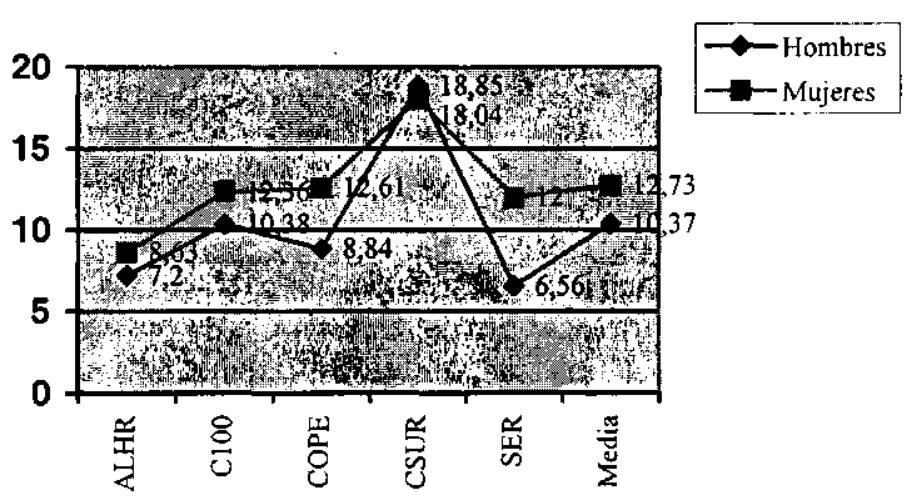

Verbos en enunciados

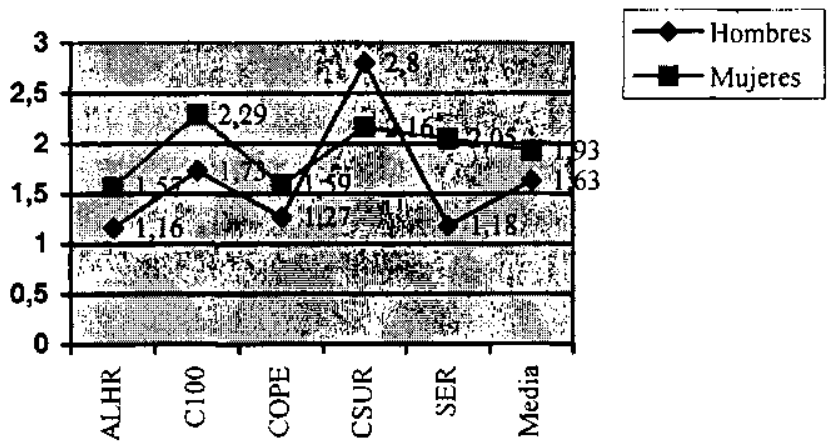


¿Tiene esta presunta mayor complejidad oracional femenina su correlato en el número de verbos que se emplean en cada enunciado? La respuesta es que sí, manteniéndose la excepción de Canal Sur. La media femenina es superior en 0,30 puntos a la masculina. Se confirma esta mayor complejidad oracional: las oraciones femeninas son más largas y tienen también más verbos.

\section{e. El discurso egocéntrico}

Una de las cuestiones claves en la distinción de los generolectos, según Tannen (1990), es el uso de las personas verbales. ¿Cuál ha sido el comportamiento de éstas en nuestra muestra?

$\mathrm{Si}$ atendemos al uso de la primera persona de singular (yo), sin excepción alguna, los hombres usan con más frecuencia la persona verbal egocéntrica, con una diferencia media de un $6,91 \%$. Llama la atención el caso particular de la Cadena SER, donde esta diferencia se dispara hasta el $18,07 \%$.

\section{Discurso egocéntrico}

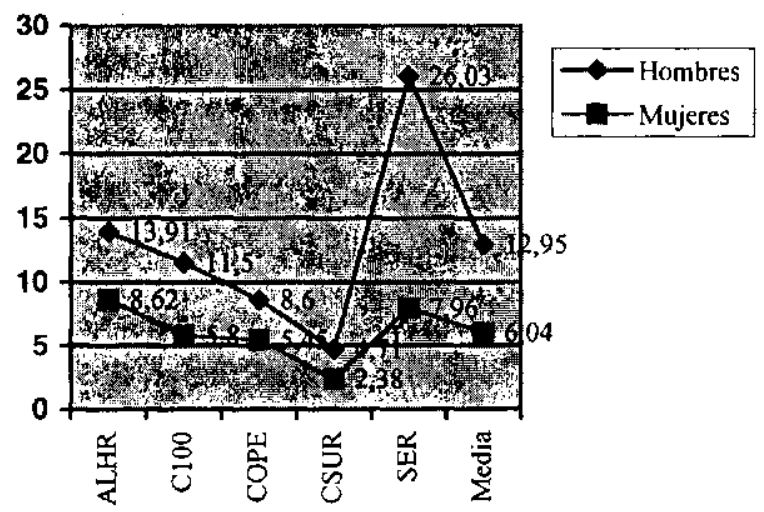

\section{f. El discurso cooperativo}

Analizando por el contrario el uso de las personas verbales que caracterizan el discurso cooperativo ( $2^{\mathrm{a}}$ persona del Singular y Plural, $1^{\mathrm{a}}$ persona del Plural, y las formas Vd./Vds.), se comprueba que la situación se invierte. Ahora son las mujeres las que prefieren estas personas, con una diferencia promedio de $9,46 \%$ a favor de las mujeres. Es cierto que en las muestras de la Cadena 100 y Canal Sur el grupo masculino utiliza con más frecuencia las formas llamadas aquí cooperativas, pero su diferencia, del orden del $2 \%$ y $1 \%$ respectivamente, se relativiza a la vista de los datos aportados por el análisis de las muestras de Alhamilla Radio, la Cadena COPE, y la Cadena SER, sensiblemente superiores. 


\section{Discurso cooperativo}

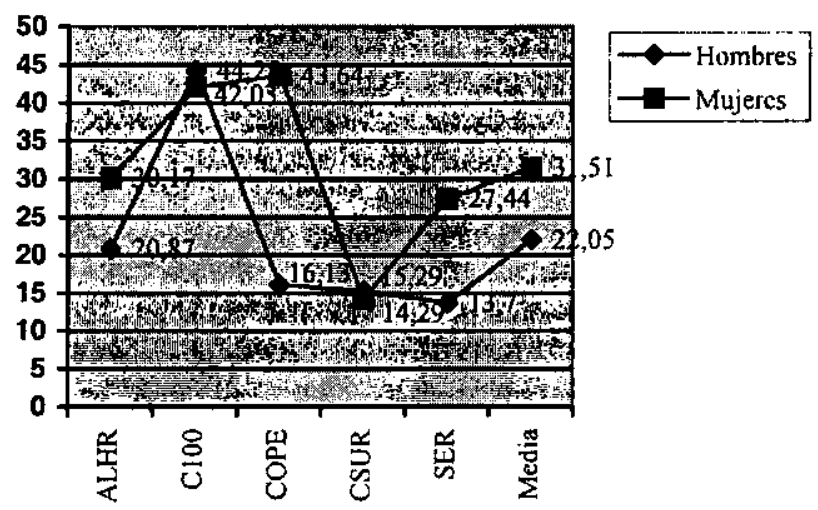

El análisis de unas formas y otras por separado nos da el valor absoluto del discurso egocéntrico y del discurso cooperativo. Pero todos, hombres y mujeres, utilizamos ambos tipos de discurso. En mi opinión, si establecemos la relación entre ambos índices por medio de su diferencia, obtendremos un dato aún más fidedigno del nivel de egocentrismo o cooperación en el uso de las personas verbales en ambos sexos.

La aplicación de esta diferencia no deja lugar a la duda: las mujeres siempre son más cooperativas que los hombres, es decir, en relación con el uso de la primera persona del singular, con más frecuencia integran al interlocutor en su discurso. Al contrario, los hombres se preocupan menos del interlocutor y cuentan más sobre sí mismos, destacando el caso extremo de la Cadena SER, en el que el resultado de esta prueba subraya una cooperación negativa, es decir, un discurso egocéntrico neto.

Discurso cooperativo - Discurso egocéntrico

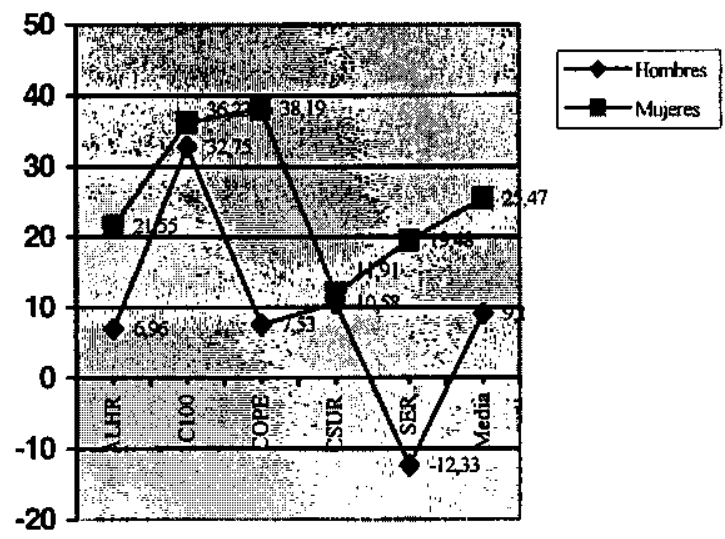




\section{CONCLUSIONES}

A mi parecer, ha quedado demostrado a lo largo de este estudio la existencia de diferencias sociolingüísticas entre sexos en el uso verbal. Los datos estadísticos apoyan la teoría de los generolectos.

Recapitulando, hemos observado cómo, si bien en esta muestra los textos producidos por los hombres poseen una densidad verbal ligeramente superior mayor número de verbos-, ello no implica una mayor variedad verbal o mayor complejidad oracional a la ofrecida por el grupo femenino. Muy al contrario, se constata que las mujeres emplean un repertorio de verbos más rico que los hombres.

Pasando de lo cuantitativo a lo cualitativo, se observa que los verbos empleados por los hombres se refieren más frecuentemente a acciones -un 7,51\% más-. Junto con el dato de la longitud verbal -enunciados más largos entre las mujeres y con mayor número de verbos- que el grupo masculino, esto indica, como ya apunta la teoría de los generolectos de Tannen, que el grupo masculino tiende a contar, y más frecuentemente sobre sí mismos, sobre lo que hacen en tanto que portadores de un prestigio social basado en su estatus laboral, de hombre que necesariamente trabaja y hace. La consecuencia lógica es el mayor porcentaje de verbos de acción y egocéntricos, de verbos conjugados en primera persona del singular: más del doble en los hombres $(12,95 \%)$ que en las mujeres $(6,04 \%)$.

Sólo decir que "las mujeres hablan más" no se ajusta exactamente a la realidad. Hablan más, pero con mayor riqueza verbal y mayor complejidad oracional - mayor número de verbos por enunciado. La cara femenina del uso de los verbos en el discurso descansa en las formas cooperativas: primera persona del plural, "nosotras/os", promoviendo espíritu de grupo, segunda persona del singular y plural, incluidas las formas de cortesía $\mathrm{Vd} . / \mathrm{Vds}$, incluyendo al interlocutor en la conversación. El discurso femenino usa un $9,46 \%$ más de estas formas verbales cooperativas, y la diferencia entre ambos tipos de personas egocéntricas frente a cooperativas arroja un contundente $16,37 \%$ más de discurso cooperativo a favor de las mujeres.

Podrían analizarse más variables con respecto al uso de los verbos -tiempos verbales, significado de los verbos, perifrasis, etc.-, pero no cabe duda de que el factor definitorio de los dos tipos de discurso, egocéntrico y cooperativo, es el uso de las personas verbales. Probablemente las diferencias entre discurso egocéntrico masculino y cooperativo femenino irán acortándose a medida que la mujer continúe incorporándose al mundo del trabajo tradicionalmente masculino y gane en confianza en este mundo. Sin embargo, si la mujer no se siente acogida en este mundo, no es de extrañar que los hombres tengan que escuchar un cooperativo "Tú no me entiendes". 


\section{REFERENCIAS BIBLIOGRÁFICAS}

Ávila, R. (1992), Difusión Internacional del Español por Radio y TeleVisión (DIES-RTV): Procedimiento para recopilar el corpus por paises, México D.F., en http://www.colmex.$\mathrm{mx}$ /paginas_personalizadas/CELL/Ravila/.

- (1997), Televisión internacional, lengua internacional, en VV. AA., Intervenciones en el Primer Congreso Internacional de la Lengua Española. Zacatecas, Centro Virtual Cervantes. (http://cvc.cervantes.es/actcult/congreso/).

- (2000), LEES: Lector - Escritor. México: El Colegio de México e Instituto Nacional para la Educación de Adultos.

Cedergren, H. J. (1983), Sociolingüistica, en López Morales, H. (dir.), Introducción a la lingüística actual. Madrid: Playor, $2^{n}$ ed., 1988, 147-165.

García Moutón, P. (1999), Cómo hablan las mujeres. Madrid: Arco/Libros.

Lak off, R. (1977), Women's Language. Language and Style, 10, 222-247.

- (1981), El lenguaje y el lugar de la mujer. Barcelona: Hacer.

López Morales, H. (1994), Métodos de investigación lingüistica. Salamanca: Ediciones Colegio de España.

Romaine, S. (1994), Language in Society. Oxford: Oxford University Press (trad. esp. de J. Borrego Nieto. El lenguaje en la sociedad. Barcelona: Ariel, 1996).

Tannen, D. (1990), You Just Don't Understand Me: Men and Women in Conversation. Nueva York: William Morrow (trad. esp. Tú no me entiendes. Bucnos Aires - Madrid: Javier Vergara Editor, 1991). 